\title{
Moving tuberculosis vaccines from theory to practice
}

Peter Andersen ${ }^{1,2 *}$ and Thomas J. Scriba ${ }^{3 *}$

Abstract | Tuberculosis (TB) vaccine research has reached a unique point in time. Breakthrough findings in both the basic immunology of Mycobacterium tuberculosis infection and the clinical development of TB vaccines suggest, for the first time since the discovery of the Mycobacterium bovis bacillus Calmette-Guérin (BCG) vaccine more than a century ago, that a novel, efficacious TB vaccine is imminent. Here, we review recent data in the light of our current understanding of the immunology of TB infection and discuss the identification of biomarkers for vaccine efficacy and the next steps in the quest for an efficacious vaccine that can control the global TB epidemic.

\section{Incipient TB}

A state of Mycobacterium tuberculosis infection in which the host is likely to progress to active tuberculosis (TB) disease but has not yet manifested clinical symptoms, radiographic abnormalities or microbiological evidence of active disease. Can be detected using transcriptomic or proteomic biomarkers of inflammation.
${ }^{1}$ Center for Vaccine Research, Statens Serum Institut, Copenhagen, Denmark.

${ }^{2}$ Department of Immunology and Microbiology, University of Copenhagen, Copenhagen, Denmark.

${ }^{3}$ South African Tuberculosis Vaccine Initiative, Institute of Infectious Disease and Molecular Medicine and Division of Immunology, Department of Pathology, University of Cape Town, Cape Town, South Africa.

*e-mail:pa@ssi.dk; thomas.scriba@uct.ac.za

https://doi.org/10.1038 s41577-019-0174-z
Tuberculosis (TB) is among the top ten causes of death overall and is the leading cause of death owing to infection with a single type of pathogen ${ }^{1}$. It is estimated that almost one-quarter of the global population, between 2 billion and 3 billion people, has been infected with Mycobacterium tuberculosis (Mtb) and may be at risk of progression to $\mathrm{TB}^{2}$. Up to $80 \%$ of the lifetime risk of progression to disease is thought to occur in the first 2 or 3 years after infection ${ }^{3}$. In 2017, an estimated 10 million people developed TB and 1.6 million people died from the disease ${ }^{1}$.

It is now appreciated that Mtb infection does not represent a single, uniform state and that the historical division of TB into either latent (latent TB infection (LTBI)) or active TB has gravely underappreciated the complex and dynamic nature of the host-pathogen interactions ${ }^{4-6}$. Progression from Mtb infection to clinical disease appears to transition via a number of continuous asymptomatic infection states that have previously been classified as LTBI, which include the asymptomatic states recently termed incipient TB and subclinical TB, before active, clinical TB disease manifests ${ }^{7,8}$. Further, within an individual host, Mtb-infected lesions in the lung or draining lymph nodes do not develop in a uniform synchronized manner but independently and therefore represent a spectrum of pathology that can span all stages from sterile, calcified granulomas through to caseous, necrotic lesions with exceedingly high bacterial burdens'. It is important to consider both the complexity of the human-Mtb interactions and the magnitude and diversity of the global epidemic as a backdrop to the challenges faced by vaccine development. Given that in some high incidence areas the majority of the adult population is infected, classic prophylactic vaccination (before any exposure to the pathogen) is applicable for only a proportion of the individuals in need. Therefore, $\mathrm{TB}$ vaccine development efforts are currently focused on developing vaccines for the following administration regimens: prophylactic vaccination, which is a vaccine administered to individuals in order to prevent Mtb infection or clinical disease (prophylactic vaccines can be either priming vaccines such as Mycobacterium bovis bacillus Calmette-Guérin (BCG) (see BOX 1) used in neonates or booster vaccines for later administration); postexposure vaccination, which is a vaccine administered to Mtb-infected individuals to prevent the development of active disease (many priming and booster vaccines are currently developed for postexposure administration owing to their ability to boost and supplement the naturally occurring infection-promoted responses); and therapeutic vaccination, which is a vaccine administered to individuals with clinical disease in combination with or after antibiotic treatment to prevent recurrence of disease. Development of both prophylactic and postexposure vaccines is actively being pursued with several candidates in clinical trials, but therapeutic vaccines are also receiving increasing attention.

Five years ago, the results of a large phase IIb efficacy trial of the first TB booster vaccine candidate tested in infants were published. Vaccination of 4-6-month-old infants, who had received neonatal BCG vaccination, with MVA85A induced no additional protection against Mtb infection or active TB beyond that observed in the placebo arm of the study ${ }^{10}$. This result was a great disappointment to both the TB vaccine research community and funders and a call to action for researchers in basic and applied vaccine development. Today, we are witnessing immense progress in both preclinical and clinical TB vaccine research, including the first proofof-concept study showing that revaccination with BCG can protect adolescents from sustained Mtb infection ${ }^{11}$ and that the subunit vaccine $\mathrm{M} 72 / \mathrm{ASO}_{\mathrm{E}}$ provides protection against the development of TB disease in Mtbinfected adults ${ }^{12}$. Here, we discuss recent breakthroughs 


\section{Box 1 | The BCG vaccine and variation in its efficacy}

Mycobacterium bovis bacillus Calmette-Guérin (BCG) has been in use for more than 80 years and is the world's most widely administered vaccine. BCG is the collective name for multiple daughter strains of an attenuated strain of Mycobacterium bovis ${ }^{88}$ (the pathogen responsible for tuberculosis (TB) in cattle) that lacks the genetic segments encoding a number of virulence factors and important $T$ cell antigens, such as ESAT6 and CFP10, which are part of the ESX1 secretion system ${ }^{89}$. Vaccination with BCG results in a localized and self-limiting infection that exposes the immune system to a complex antigen repertoire including mycobacterial proteins, lipids and glycolipids and induces both conventional MHC-restricted and unconventional T cell responses as well as antibody responses and trained immunity ${ }^{90-92}$. Vaccination with BCG consistently provides a high degree of protection in infants and toddlers against highly lethal meningeal TB and miliary $\mathrm{TB}^{93}$ and appears to last $10-15$ years ${ }^{94}$, although a small number of studies show much longer persistence of protective effects, up to 40 or 50 years after vaccination ${ }^{95,96}$. However, in the adult population, BCG vaccination provides only highly variable protection against pulmonary TB, ranging from $0 \%$ to $80 \%$, which appears to correlate with geographical latitude (vaccination efficacy is poorest in the regions closest to the equator) and may be related to immunological sensitization to atypical, non-tuberculous mycobacteria, which are particularly abundant in tropical environments ${ }^{97}$. A recent systematic review of randomized controlled trials of BCG vaccination shows that prior infection with Mycobacterium tuberculosis (Mtb) or sensitization with environmental mycobacteria is associated with a reduced efficacy of $\mathrm{BCG}$ vaccination against pulmonary $\mathrm{TB}^{98}$. Environmental mycobacteria are likely to induce a low level of anti-Mtb immunity owing to homology between species within the genus Mycobacterium that can mask or block the replication of BCG necessary for sufficient induction of immunity ${ }^{76,99}$ (FIC. 2). There are hundreds of atypical mycobacteria with different levels of cross reactivity with BCG and with different geographical distributions ${ }^{100,101}$. Furthermore, the focus on these environmental mycobacteria as a reason for the sensitization has distracted the focus from Mtb infection as a source of prior immune sensitization with strong effects on BCG efficacy. In geographical regions with a high prevalence of mycobacteria, where the lowest efficacy of BCG has been reported, Mtb infection represents a very significant source of sensitization, with $50-80 \%$ of the population showing immunological sensitization suggestive of Mtb infection ${ }^{98}$. Despite decades of interest in the effects of environmental mycobacteria on BCG vaccine efficacy, this issue remains challenging to investigate given the large number of species in different parts of the world. The availability of well-curated and standardized antigen preparations from different atypical mycobacteria should be prioritized to facilitate such research.

\section{Subclinical TB}

A state of Mycobacterium tuberculosis infection in which the host has radiographic abnormalities or microbiological evidence of active tuberculosis (TB) disease but has not yet manifested clinical symptoms of active disease

Priming vaccines Vaccines that mediate sensitization or stimulation of an immune response with antigen for the first time; that is, the vaccines prime the immune response.

\section{Booster vaccines}

Vaccines that are typically given after an earlier priming vaccine and further stimulate an immune response that

already exists to an antigen to increase the response

magnitude or modulate the function of the response;

that is, the vaccines boost the pre-existing immune response. in our understanding of the mechanism of protective immune responses, provide an overview of the vaccine candidates in clinical trials and discuss whether it is time to reconsider BCG revaccination as part of a future improved TB vaccine strategy.

\section{Immune responses to Mtb}

Mtb can establish infection in susceptible individuals after the inhalation of a single or a few bacteria that are taken up by alveolar macrophages. The pathogen has developed a refined set of evasion mechanisms that delay bacterial transport to the regional lymph node and allow it to evade host cellular immunity, giving it sufficient time to establish a productive infection ${ }^{13-15}$. The result is a delayed onset of the natural adaptive immune response observed both in animal models of $\mathrm{TB}^{16}$ and in human clinical $\mathrm{TB}^{17,18}$.

One of the primary roles of vaccination is to establish efficient and long-lived immune memory in order to shorten the interval between infection and the onset of an adaptive immune response at the site of infection, such that the infection can be controlled rapidly and spreading to secondary sites is avoided. In humans, the first exposure to Mtb typically occurs after the immune response has been primed by other mycobacterial encounters, either in the form of BCG vaccination or environmental mycobacteria. As a result, TB vaccine strategies should consider how prior induction of $\mathrm{T}$ cells (and other immune responses) by these exposures may influence the function, trafficking and survival of vaccination-induced responses and their effectiveness against Mtb. Furthermore, in settings with very high rates of Mtb infection, such responses must be able to resist the effects of repeated reinfection and long-term continuous antigen exposure from this chronic infection.

The role of $\mathrm{CD}^{+} \mathrm{T}$ cells. Recent data in animal models suggest that vaccine-induced $\mathrm{CD} 4^{+}$cells of the Thelper $17\left(\mathrm{~T}_{\mathrm{H}} 17\right)$ cell subtype, which naturally traffic to the airways, can accelerate the recruitment of protective $\mathrm{T}_{\mathrm{H}} 1$ cell $^{19-21}$. In fact, a recent study of a rhesus macaque model of pulmonary vaccination showed that vaccination with BCG induces pulmonary $\mathrm{T}_{\mathrm{H}} 1$ cells and/or $\mathrm{T}_{\mathrm{H}} 17$ cells, which co-express IFN $\gamma$, TNF, IL-2 and IL-17 and protect against infection upon repeat low-dose challenge with $\mathrm{Mtb}^{22}$. When $\mathrm{CD}^{+} \mathrm{T}$ cells arrive at the site of infection, they encounter aggregates of Mtb-containing macrophages and other immune cells and together form the tight cellular structure referred to as the granuloma. The $\mathrm{CD}^{+} \mathrm{T}$ cells secrete cytokines, which activate infected macrophages to control bacterial growth and attract more immune cells to the granuloma (reviewed elsewhere $^{23}$ ).

Most vaccine research has focused on $\mathrm{T}_{\mathrm{H}} 1$ cells and the effector cytokine IFN $\gamma$ as a readout for successful vaccination and a potential indicator of vaccine efficacy. However, it is clear from animal studies ${ }^{22,24,25}$ that expansion beyond the narrow focus on IFN $\gamma$ is necessary to identify new biomarkers (also called immune correlates of protection (COP); see BOX 2) to support vaccine evaluation and optimization. This is also supported by conflicting data on the role of IFN $\gamma$ in human studies. A study of COP in the participants of the MVA85A phase IIb trial suggested that higher frequencies of BCG-reactive IFN $\gamma$-secreting cells, as quantified by ELIspot assay, were associated with a reduced risk of developing $\mathrm{TB}^{26}$. By contrast, the MVA85A booster vaccine referred to above induced long-lived $\mathrm{CD}^{+}{ }^{+} \mathrm{T}$ cells that co-expressed IFN $\gamma$, TNF and IL-2 (REF. ${ }^{27}$ ), a functional subset of cells termed polyfunctional by many in the field, but this subset did not afford protection ${ }^{10}$. Similarly, in a study of 10 -weekold infants that were vaccinated with BCG at birth, there was no association between the frequencies of BCG-reactive $\mathrm{T}_{\mathrm{H}} 1$ cells or the co-expression patterns of IFN $\gamma$, TNF and IL- 2 of these cells and subsequent risk of developing $\mathrm{TB}^{10,26-28}$. Collectively, these studies suggest that $\mathrm{T}_{\mathrm{H}} 1$ cell responses are necessary but not sufficient to mediate protection against $\mathrm{Mtb}$ and that other functions and characteristics of T cells, and perhaps other arms of immunity, are involved in protection against TB.

Recently, the expression of CD153, a surface molecule of the TNF superfamily that is expressed by Mtbspecific $\mathrm{CD}^{+} \mathrm{T}$ cells during infection, was suggested as a promising marker of protection in animal models. CD153 was also found to be expressed by Mtb-specific 
Correlates of protection (COP). A measurable feature, often a functional characteristic of an immune response, that associates with protection against becoming infected and/or developing disease.

\section{ELISpot assay}

(Enzyme-linked

immunosorbent spot assay). A type of immune assay that quantifies the frequency of protein-secreting single cells on the basis of enzyme-linked detection of protein spots on immune-absorbent membranes.

\section{Box 2 | Immune correlates of vaccine protection}

The discovery of vaccine-associated correlates of protection (COP) is possible only if samples from successful placebocontrolled efficacy trials of a tuberculosis (TB) vaccine are available. This is because COP discovery requires the comparison of immune responses in vaccinated and unvaccinated individuals who are protected against Mycobacterium tuberculosis (Mtb) and in those who are not protected against Mtb (for example, individuals with active TB) ${ }^{102,103}$. The lack of such COP has been a major limitation in TB vaccine development. A robust and validated COP could predict vaccine efficacy and allow significantly more efficient testing of vaccine candidates while facilitating the rational design of improved vaccines and strategies ${ }^{104}$. The exciting efficacy signals provided by the phase $\mathrm{llb}$ trial of the subunit vaccine H4:IC31 (REF. ${ }^{11}$ ) versus Mycobacterium bovis bacillus Calmette-Guérin (BCG) revaccination and the phase llb trial of the subunit vaccine $M 72 / A S O 1_{E}\left(R_{E F}{ }^{12}\right.$ ) bring about a new phase in TB vaccinology, as they unlock the possibility of identifying vaccine-associated COP against Mtb infection or TB disease.

In the phase llb trial of MVA85A in infants, the frequency of $\mathrm{HLA}-\mathrm{DR}^{+} \mathrm{CD}^{+} \mathrm{T}$ cells was identified as a correlate of risk of progression to TB, and the level of Ag85A-specific $\lg \mathrm{G}$ and frequencies of BCG-reactive IFN $\gamma$-secreting cells were identified as correlates of non-progression ${ }^{26}$, demonstrating that the identification of $C O P$ is possible. The figure shows a suggested framework for utilizing newly identified immunological correlates of protection in TB vaccine development. Prospective validation of these COP in future efficacy trials (phase $\mathrm{Ilb} / \mathrm{III}$ ) is necessary to confirm their validity as true predictors of vaccine protection (bottom). Translation of the COP to appropriate and highly tractable animal models of TB vaccination (for example, non-human primates and mice), which should be done alongside infectious challenge studies to confirm in vivo protection, would allow the discovery of the mechanistic underpinnings of protective immunity against $\mathrm{Mtb}$ (see the figure, top) and faciliate the preclinical selection of vaccine candidates. Measurement of such COP in phase I or II clinical trials of novel vaccine candidates could also be used to accelerate selection of candidates for efficacy trials (see the figure, right). Similarly, the identification of COP will facilitate a more rapid and cheaper readout of efficacy in diverse geographical or epidemiological settings for vaccine candidates for which evidence of efficacy may be limited to one setting.

In the trials of $\mathrm{H} 4: \mathrm{IC} 31-\mathrm{BCG}$ and M72/ASO1 $1_{\mathrm{E}}$ discussed above ${ }^{11,12}$, blood samples for the discovery of COP were collected and stored, and a consortium has been established to develop and execute the analyses. Universal application of newly identified COP may ultimately be more challenging than many expect; it is quite possible that mechanisms of protection induced by distinct vaccines are different or that the translation between species is problematic. Ultimately, newly discovered COP would require prospective validation in future efficacy trials to confirm their validity as predictors of vaccine protection, known as surrogates of protection (reviewed elsewhere ${ }^{102}$ ).

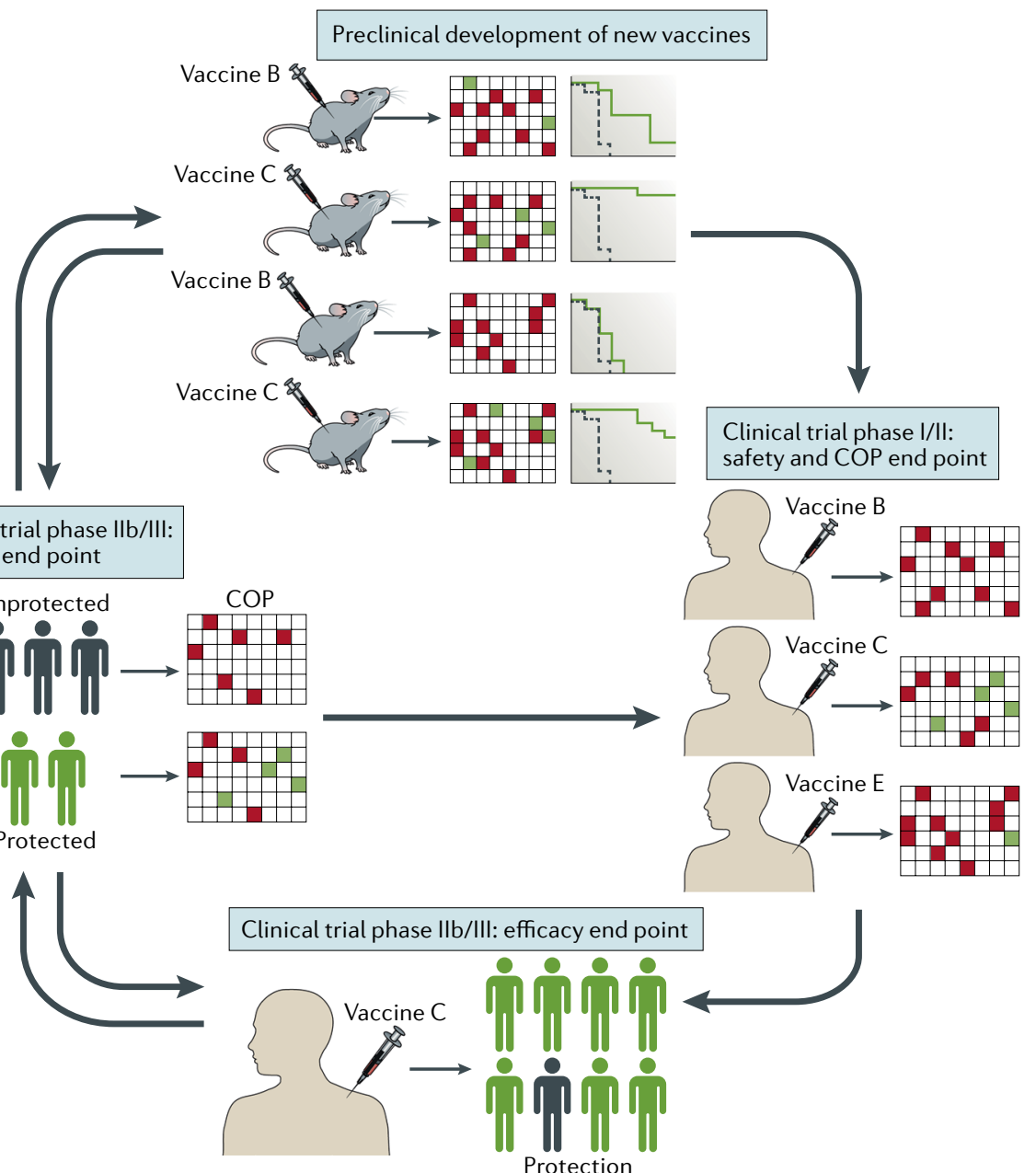


Inducible bronchusassociated lymphoid tissue A tertiary lymphoid structure that consists of lymphoid follicles in the lungs or bronchus and that is a site for priming immune responses
$\mathrm{CD}^{+} \mathrm{T}$ cells in humans who successfully control $\mathrm{Mtb}$ infection $^{29}$. This molecule is an example of the new candidate biomarkers of protective immunity that should be considered in analyses of immune COP in the context of vaccine trials.

The role of $\mathrm{CD8}^{+}$cells. Mtb-specific $\mathrm{CD}^{+} \mathrm{T}$ cell responses increase during disease progression with kinetics that appear to positively correlate with the bacterial burden ${ }^{30,31}$, but their role in protective immunity to $\mathrm{Mtb}$ is unclear. Evidence that $\mathrm{CD}^{+}$cells may play a protective role comes from a non-human primate (NHP) study in which $\mathrm{CD}^{+} \mathrm{T}$ cells were depleted, which resulted in compromised BCG vaccine-induced immune control of $\mathrm{Mtb}^{32}$. However, recent data from murine models suggest that even very high numbers of vaccine-induced $\mathrm{CD}^{+} \mathrm{T}$ cells that are specific for antigens involved in protective immunity fail to recognize Mtb-infected macrophages or affect Mtb proliferation in animal infection studies ${ }^{33,34}$. Similarly, antigen-specific $\mathrm{CD}^{+} \mathrm{T}$ cells induced by an adenovirusbased TB vaccine in humans failed to recognize Mtbinfected dendritic cells in vitro ${ }^{35}$. Although the subject of numerous studies, the role of $\mathrm{CD}^{+} \mathrm{T}$ cell responses in protective immunity against $\mathrm{TB}$ therefore still remains unresolved.

The role of B cells. Antigen-specific antibodies, and their functional attributes in immunity against $\mathrm{Mtb}$, have recently received increasing attention. Compelling evidence shows marked differences in the plasma levels of natural mycobacteria-specific IgG or IgA and their glycosylation profiles and $\mathrm{Fc}$ functions when comparing individuals with LTBI and patients with active $\mathrm{TB}^{36,37}$. Further, a recent study of a rhesus macaque model of pulmonary BCG vaccination showed that high levels of antigen-specific IgA in bronchoalveolar lavage fluid were associated with protection against Mtb infection and disease $\mathrm{e}^{22}$.

Mtb escape mechanisms. In addition to delaying the onset of adaptive immune responses, Mtb has also evolved a set of escape mechanisms aimed at inhibiting $\mathrm{CD}^{+} \mathrm{T}$ cell activation during later stages of the infectious process ${ }^{38}$. Examples include the downregulation of certain target antigens to very low levels ${ }^{39}$ and the active transfer of immunodominant antigens to uninfected bystander dendritic cells and macrophages ${ }^{40}$. The outcome of this host-pathogen stand-off is bacterial survival in a state of latent infection. It is notable that established latent infection seems to provide significant protection against reinfection in classical epidemiological studies ${ }^{41,42}$ and in NHP models ${ }^{43}$, a phenomenon that provides evidence for protective natural immunity against Mtb. We note that it is possible that immune mechanisms necessary for protection against the establishment of Mtb infection may be different from those required for successful long-term containment of an established Mtb infection such that progression to disease is averted. Ongoing studies of vaccine-induced COP, described below, will provide important insights into this.
The diversity of the $\mathrm{CD4}^{+} \mathrm{T}$ cell response to tuberculosis. For protection against $\mathrm{TB}$, the $\mathrm{CD} 4^{+} \mathrm{T}$ cell subset is of major interest. $\mathrm{CD}^{+} \mathrm{T}$ cells differentiate into $\mathrm{T}$ central memory $\left(\mathrm{T}_{\mathrm{CM}}\right)$ cells that home to secondary lymphoid organs and, on the basis of their expression of adhesion molecules, most likely also to inducible bronchusassociated lymphoid tissue structures in the lung ${ }^{44}$. Upon antigen re-exposure, $\mathrm{T}_{\mathrm{CM}}$ cells differentiate into $\mathrm{T}$ effector memory $\left(\mathrm{T}_{\mathrm{EM}}\right)$ cells and effector cells of either the $\mathrm{T}_{\mathrm{H}} 1$ cell or $\mathrm{T}_{\mathrm{H}} 17$ cell lineage that migrate to and exert their effector functions in infected tissues (see FIG. 1). A proportion of these $\mathrm{T}$ cells subsequently remains in the lung as $\mathrm{T}$ tissue-resident memory $\left(\mathrm{T}_{\mathrm{RM}}\right)$ cells. An efficient frontline defence in the lung depends on both $\mathrm{T}_{\mathrm{RM}}$ cells localized in the lung before infection and newly recruited $\mathrm{T}$ effector $\left(\mathrm{T}_{\mathrm{EFF}}\right)$ cells that arrive after infection. However, for a chronic infection such as Mtb, the longevity of the immune response, that is, the ability to withstand the continuous exposure to antigen for very long periods without exhaustion, is likely of equal importance. This is where $\mathrm{T}$ stem cell memory $\left(\mathrm{T}_{\mathrm{SCM}}\right)$ cells and $\mathrm{T}_{\mathrm{CM}}$ cells play a central role because their proliferative potential can maintain the supply of tissue-homing T cells. Designing TB vaccine strategies therefore requires careful consideration of the distribution of different subsets of $\mathrm{CD} 4^{+}$ $\mathrm{T}$ cells, how they respond to repeated antigen exposure during persistent infection and their ability to traffic to and be retained within the lung, both before and during ongoing Mtb infection.

In humans, Mtb infection promotes the development of $\mathrm{CD}^{+} \mathrm{T}$ cells that span a range of differentiation states, from the most early $\mathrm{T}_{\mathrm{SCM}} \mathrm{CD}^{+}{ }^{+}$cells ${ }^{45}$ through to fully differentiated $\mathrm{T}_{\mathrm{EFF}}$ cells that predominantly express IFN $\gamma^{46-48}$. Many factors are likely to determine where in this range a given specific $\mathrm{T}$ cell response will lie, including the expression level of the particular Mtb antigen that is targeted, the stage of disease progression or host-pathogen interaction and the location of the $\mathrm{T}$ cell itself. In order to allow a conclusive interpretation of results, it is therefore essential that human studies of $\mathrm{T}$ cell function and differentiation clearly and carefully characterize the clinical phenotype of study participants to define infection stage. Overall, an increasing mycobacterial load correlates with progressive differentiation of $\mathrm{Mtb}$-specific $\mathrm{CD} 4^{+} \mathrm{T}$ cell responses away from $\mathrm{T}_{\mathrm{CM}}$ cells that secrete IL-2 and towards $\mathrm{T}_{\mathrm{EFF}}$ cells that secrete predominantly IFN $\gamma^{46-49}$. In animal models of Mtb infection, ongoing antigen exposure is a significant challenge for the host immune system and results in $\mathrm{CD}^{+} \mathrm{T}$ cell exhaustion through inhibitory receptors such as TIM3 (also known as HAVCR2) ${ }^{50}$ and the upregulation of exhaustion markers such as killer-like lectin receptor G1 (KLRG1) ${ }^{51}$. This results in the loss of selfrenewing $\mathrm{T}_{\mathrm{CM}}$ cell subsets and in functional impairment, eventually resulting in uncontrolled growth of $\mathrm{Mtb}^{52}$. In TB vaccine studies in the mouse model, it has become clear that $\mathrm{T}$ cell responses promoted by an adjuvanted vaccine formulation typically differ from Mtb-induced $\mathrm{T}$ cell responses in that they preferentially induce IL-2-producing $\mathrm{T}_{\mathrm{CM}}$ cells. Compared with $\mathrm{T}_{\mathrm{EM}}$ cells and $\mathrm{T}_{\mathrm{EFF}}$ cells induced by continuous exposure to $\mathrm{Mtb}$, these $\mathrm{T}_{\mathrm{CM}}$ cells are less likely to become terminally 


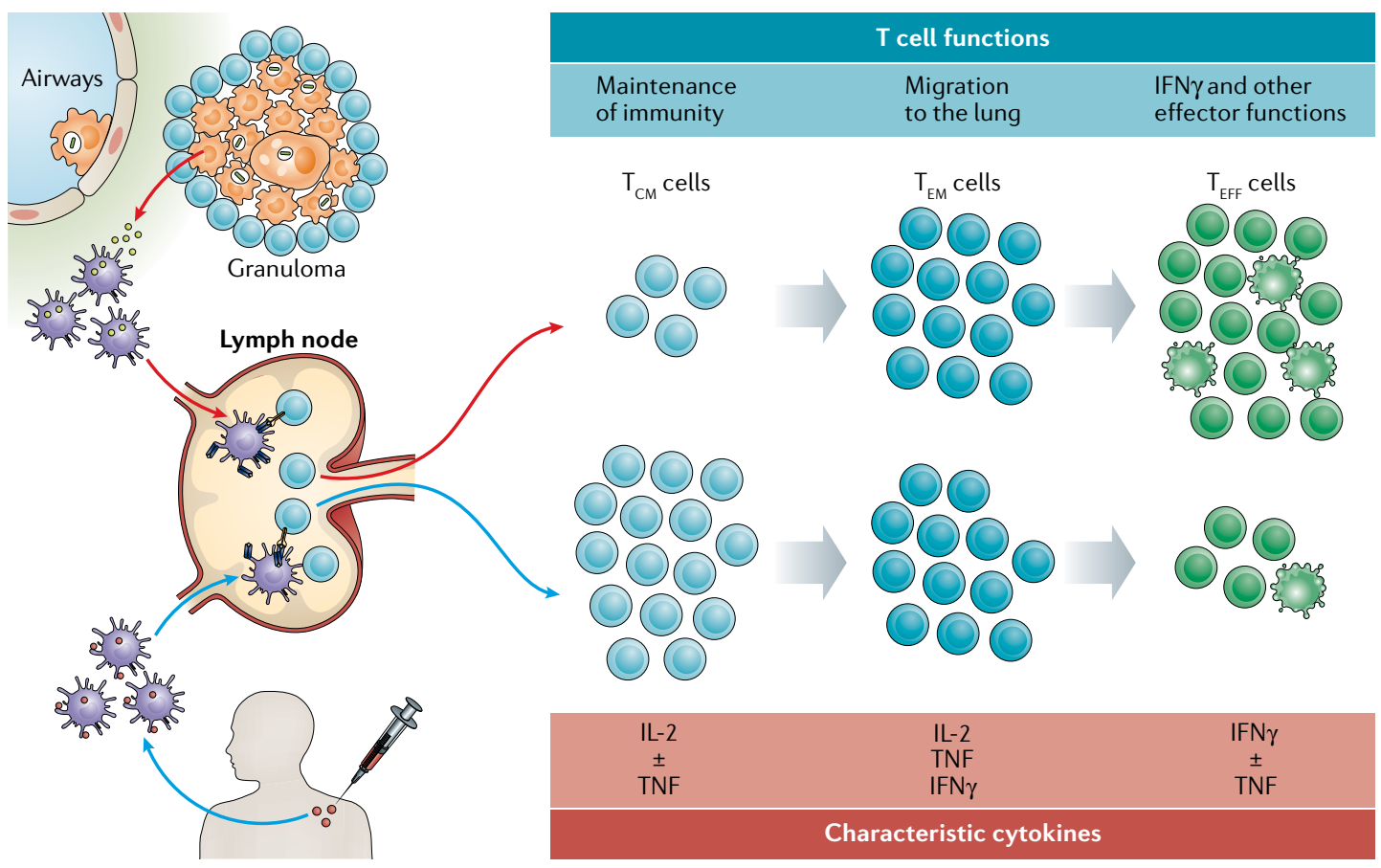

Fig. 1 | The balance between Mtb-specific T cell differentiation into either T effector memory or T central memory cells. After Mycobacterium tuberculosis (Mtb) infection of alveolar macrophages (red arrows), Mtb is transported to lungdraining lymph nodes by infected dendritic cells, initiating T cell priming or triggering the activation of pre-existing memory T cells, which appears to preferentially drive T cell differentiation towards late-stage T effector memory $\left(T_{E M}\right)$ cell and T effector $\left(T_{E F F}\right)$ cell responses. Ongoing antigen expression is likely a driver of this $T$ cell differentiation process, which favours primarily IFN $\gamma$-expressing and/or TNF-expressing T cells and little IL-2 expression. Vaccine administration in the skin or muscle promotes antigen uptake by dendritic cells, which traffic to draining lymph nodes to prime or activate T cells (blue arrows). In the case of subunit protein-adjuvant vaccines, the resulting T cell responses appear to be dominated by less differentiated T central memory $\left(\mathrm{T}_{\mathrm{CM}}\right)$ cell responses; these cells primarily express IL-2 and/or TNF. Achieving long-lived protective immunity by vaccination may require the establishment of a careful balance between $\mathrm{T}_{\mathrm{CM}}$ cell and $\mathrm{T}_{\mathrm{EM}}$ cell responses, such that a durable pool of memory cells resides in secondary lymphoid tissues while an appropriate tissue-resident population with rapid effector function is maintained in peripheral airway tissues.

differentiated, predominantly IFN $\gamma$-secreting KLRG1 ${ }^{+}$ T cells (FIG. 1).

Such vaccine-induced $\mathrm{T}$ cells therefore have the desirable ability to resist terminal differentiation, which would eventually result in functional impairment and depletion of the Mtb-specific T cell pool ${ }^{48,49,52}$. Animal models of TB that investigated $\mathrm{T}$ cell differentiation have demonstrated that BCG vaccination, similarly to Mtb infection, pushes $\mathrm{T}$ cell differentiation towards $\mathrm{T}_{\mathrm{EFF}}$ cells, which results in a failure to efficiently maintain long-term protection against $\mathrm{Mtb}^{53,54}$.

Initially, the main role of less differentiated $\mathrm{CD} 4^{+}$ $\mathrm{T}$ cells (such as $\mathrm{T}_{\mathrm{CM}}$ cells and $\mathrm{T}_{\mathrm{SCM}}$ cells) was thought to relate exclusively to their ability to resist differentiation, replenish $\mathrm{T}_{\mathrm{EM}}$ cells and maintain long-lived memory both before and after infection. Recent insights into $\mathrm{T}$ cell migration patterns have added important new facets to this interpretation. Using an intravascular staining technique, a less differentiated memory subset of T cells, which expresses the checkpoint molecule PD1 and the chemokine receptor CXCR3, was shown to enter the Mtb-infected lung parenchyma ${ }^{55}$. By contrast, the more differentiated $\mathrm{T}_{\mathrm{EFF}}$ cell subsets, characterized by the expression of KLRG1 and the fractalkine receptor $\mathrm{CX}_{3} \mathrm{CR} 1$, lose their ability to enter the lung parenchyma and to protect against $\mathrm{Mtb}^{55}$. The negative influence of a highly differentiated and strongly $\mathrm{T}_{\mathrm{H}} 1$ cell-polarized response on protection against $\mathrm{Mtb}$ is further supported by recent data from experimental animal models that investigate this question from different angles ${ }^{56-58}$.

Choosing the best antigens. Two critical and as yet unresolved questions in $\mathrm{TB}$ vaccinology are how to select the best antigens and how many antigens to include in a vaccine. The retrospective analysis of the phase IIb clinical trial of the MVA85A booster vaccine, which contains a single antigen (Ag85A), highlights this question $^{59,60}$. Given that earlier studies had shown that Ag85A is expressed at only low levels during chronic Mtb infection in mouse model ${ }^{61,62}$, it is possible that the disappointing results were due to poor antigen choice $^{61,62}$. Some of the most vaccine-relevant $\mathrm{T}$ cell antigens are virulence factors such as those associated with the ESX1 protein secretion system, which is instrumental for pathogen survival and is expressed at high levels in vivo during both the acute and chronic phase of infection ${ }^{61-63}$. Although one might assume that this high level of expression might indicate suitability as an immune target, immune responses to highly expressed antigens may eventually become exhausted during 
chronic infection. An unanswered question is whether repeated exposure or reinfection in humans who live in high-transmission settings also drives $\mathrm{T}$ cell exhaustion. Interestingly, most of the immunodominant antigens are conserved, with minimal sequence variation among different clinical strains of Mtb, indicating that the induction of $\mathrm{T}$ cell exhaustion may be an integral part of the Mtb survival strategy ${ }^{64-66}$. In a direct comparison between T cell responses specific for the ESAT6 antigen (which shows high and continuous expression during Mtb infection) and Ag85B (which is primarily expressed early during infection), the different expression profiles were found to have a profound influence on the quality of the immune response. Ag85B-specific $\mathrm{T}$ cells developed into classical CCR7 ${ }^{+} \mathrm{KLRG}^{-} \mathrm{T}_{\mathrm{CM}}$ cells after primary Mtb infection in mice, whereas ESAT6specific T cells were maintained in an effector state and gradually increased their expression of KLRG1 and lost IL-2 expression ${ }^{54,63}$. Similar differences between the differentiation state and functional capacity of human ESAT6-specific and Ag85B-specific CD4 ${ }^{+}$T cells were also observed in healthy trial participants with LTBI who were vaccinated with the $\mathrm{H} 1$ :IC31 or H56:IC31 vaccines, which contain both antigens ${ }^{63}$.

These findings are in agreement with previous reports of the influence of antigen persistence and load on the distribution of different subsets of human memory $\mathrm{T}$ cells in clinical studies of other infections or vaccines $^{67}$. A vaccine that provides a single exposure to an antigen followed by antigen clearance, such as the tetanus vaccine, primarily induces IL-2-producing $\mathrm{T}_{\mathrm{CM}}$ cells, whereas pathogens that cause contained infections that provide low but persistent antigen exposure, such as herpes simplex virus 1 , induce $T_{\mathrm{EM}}$ cells that express IFN $\gamma$, TNF and low levels of IL-2 (REF. ${ }^{67}$ ). $T_{\text {EFF }}$ cells that express only IFN $\gamma$ on the other hand are induced by infections such as cytomegalovirus that provide high and persistent antigen exposure ${ }^{67}$.

Striking the balance to achieve longevity and efficacy. As discussed above, excessive induction of $\mathrm{T}_{\mathrm{EFF}}$ cells by a vaccine modality or its antigen components may lead to impaired maintenance of memory and functional ability of the immune response, and, in the most extreme case, with very high expression of effector cytokines, such as IFN $\gamma$ or IL-17, the result can be immunopathology ${ }^{68-71}$. TB vaccine strategies therefore need to strike an optimal balance between the self-renewing $\mathrm{T}_{\mathrm{SCM}}$ cell and $\mathrm{T}_{\mathrm{CM}}$ cell subsets and the more differentiated $\mathrm{T}_{\mathrm{EM}}$ cell and $\mathrm{T}_{\mathrm{EFF}}$ cell subsets that provides an efficient first-line defence in the lung (FIG. 1). This is complicated by the large proportion of individuals with LTBI (in some high-endemic regions more than $50 \%$ of the population $)^{2}$ and extensive reinfection in high-transmission settings. Individuals with LTBI have an already established $\mathrm{T}$ cell response and represent a challenging population in which vaccine modalities and doses intended for initial priming in naive hosts may be suboptimal ${ }^{72}$. A recent analysis of the literature on the pathogenesis of human TB before antibiotics were introduced furthermore suggests that immune responses required to prevent progression to reactivation TB (that is, progression of established LTBI to active disease) are likely to be different from those required to control or prevent the establishment of the primary infection ${ }^{9}$. This follows from the argument that, in the case of progression to reactivation $\mathrm{TB}$, a successful immune response would need to protect against tissue damage and cavitation. A recent interim analysis of the ongoing phase IIb trial of the subunit vaccine $\mathrm{M} 72 / \mathrm{ASO} 1_{\mathrm{F}}$ as a postexposure vaccine which showed a vaccine efficacy of $54 \%$ against progression to TB relative to placebo ${ }^{12}$, clearly shows that efficacious vaccine modalities in pre-sensitized populations are possible. Delineating the functional, phenotypic and differentiation characteristics of $\mathrm{T}$ cell responses induced by the two antigens in this vaccine (Mtb32A and Mtb39A) will be critical for our understanding of immune COP against TB.

\section{Tuberculosis vaccines in clinical trials}

The development of an efficacious TB vaccine strategy relies on a healthy pipeline of $\mathrm{TB}$ vaccine candidates that represent a diverse repertoire of formulations and mycobacterial antigens and that induce a broad range of immune responses with different characteristics. Eleven TB vaccine candidates (TABLE 1) are currently in clinical testing for prophylactic, postexposure or therapeutic indications.

Whole cell vaccines - live. Live, attenuated whole cell vaccines were initially developed as prophylactic, priming vaccines with the aim to replace BCG-prime vaccination in infants, but they are now also being assessed as postexposure vaccines in adolescents and adults. Two of these vaccines, the recombinant BCG vaccine VPM1002 and the live, attenuated Mtb vaccine MTBVAC, are currently in clinical trials. Both induce a complex and diverse immune response to many antigens, which may offer an advantage over subunit vaccines that have a response restricted to a few antigens. However, such live vaccines are likely to be subject to the same interference caused by prior immunological sensitization by non-tuberculosis mycobacteria (NTMs) as reported for BCG. VPM1002 is also being assessed as a postexposure vaccine for the prevention of recurrence of active TB.

Whole cell vaccines - inactivated. On the basis of a classical vaccine development paradigm, these products, which include RUTI, Mycobacterium vaccae-based vaccines and the Mycobacterium obuense-based DAR-901 vaccine, utilize killed whole mycobacterial cells or mycobacterial cell extracts to safely induce complex immune subsets against multiple Mtb antigens. RUTI and $M$. vaccae-based vaccines are primarily being pursued as therapeutic vaccines, while DAR-901 is being developed as both a prophylactic and a therapeutic vaccine.

Adjuvanted protein subunit vaccine. Subunit vaccines are based on protein antigens administered with adjuvants. These are primarily developed as prophylactic or postexposure vaccines that boost responses that were initially primed by BCG or Mtb infection for preventing the establishment of Mtb infection, active TB or recurrent disease. Subunit vaccines that are currently in 
Table 1 | Tuberculosis vaccine candidates that are currently in clinical trials or have recently completed clinical trials

\begin{tabular}{|c|c|c|c|c|c|c|c|}
\hline $\begin{array}{l}\text { Candidate and } \\
\text { developers }\end{array}$ & $\begin{array}{l}\text { Antigens (genes } \\
\text { and function), } \\
\text { vector or } \\
\text { formulation }\end{array}$ & $\begin{array}{l}\text { Mode of } \\
\text { immunization }\end{array}$ & $\begin{array}{l}\text { Vaccine- } \\
\text { induced T cell } \\
\text { response }\end{array}$ & $\begin{array}{l}\text { Vaccine- } \\
\text { induced } \\
\text { antibody } \\
\text { response }\end{array}$ & Efficacy & $\begin{array}{l}\text { Development } \\
\text { status }\end{array}$ & Refs \\
\hline \multicolumn{8}{|c|}{ Whole cell vaccines - live } \\
\hline $\begin{array}{l}\text { VPM1002; Max } \\
\text { Planck Institute, } \\
\text { Vakzine Projekt } \\
\text { Management, } \\
\text { TBVI, Serum } \\
\text { Institute of India }\end{array}$ & $\begin{array}{l}\text { Recombinant BCG } \\
\text { (BCG } \Delta \text { ureC:: hly: } \\
\text { expresses the } \\
\text { listeriolysin gene to } \\
\text { promote lysosome } \\
\text { escape, while the } \\
\text { urease } C \text {-encoding } \\
\text { gene ureC, } \\
\text { which reduces } \\
\text { acidification of } \\
\text { the phagosomal } \\
\text { compartment, has } \\
\text { been deleted) }\end{array}$ & $\begin{array}{l}\text { Prophylactic, } \\
\text { postexposure } \\
\text { and therapeutic }\end{array}$ & $\begin{array}{l}\mathrm{CD}^{+} \text {and } \\
\mathrm{CD} 8^{+} \mathrm{T} \text { cells } \\
\text { expressing } \\
\text { different } \\
\text { combinations } \\
\text { of IFN } \gamma, \mathrm{TNF} \text { or } \\
\text { IL-2; unusual } \\
\text { subset of } \\
\text { IL-17-expressing } \\
\mathrm{CD} 8^{+} \text {T cells }\end{array}$ & Not reported & NA & $\begin{array}{l}\text { Phase II completed; } \\
\text { phase III trial in } \\
\text { newborn babies to } \\
\text { commence soon }\end{array}$ & \\
\hline $\begin{array}{l}\text { MTBVAC; } \\
\text { Universidad } \\
\text { de Zaragoza, } \\
\text { BIOFABRI, TBVI }\end{array}$ & $\begin{array}{l}\text { Live, attenuated } \\
\text { Mtb vaccine with } \\
\text { two independent } \\
\text { and stable } \\
\text { deletions in } \\
\text { genes encoding } \\
\text { the virulence } \\
\text { factors phoP and } \\
\text { fadD26 }\end{array}$ & $\begin{array}{l}\text { Prophylactic } \\
\text { and } \\
\text { postexposure }\end{array}$ & $\begin{array}{l}\mathrm{CD}^{+} \text {and } \mathrm{CD} 8^{+} \\
\text {T cells that } \\
\text { express IFN } \gamma \text {, } \\
\text { TNF and IL-2 }\end{array}$ & Not tested & NA & $\begin{array}{l}\text { Phase II trials in } \\
\text { adults and newborn } \\
\text { babies ongoing } \\
\text { (ClinicalTrials.gov } \\
\text { NCT02933281 and } \\
\text { NCT03536117) }\end{array}$ & $\begin{array}{r}\text { (Tameris et al., } \\
\text { manuscript in } \\
\text { preparation) } \\
107-109\end{array}$ \\
\hline
\end{tabular}

Whole cell vaccines - inactivated

$\begin{array}{ll}\text { RUTI; Archivel } & \begin{array}{l}\text { Detoxified, } \\ \text { fragmented Mtb } \\ \text { Farma }\end{array} \\ \text { cells delivered in }\end{array}$
liposomes

M. vaccae-based vaccines; Anhui Zhifei Longcom

Whole cell, heatkilled M. vaccae

DAR-901;

Dartmouth, Geisel School of Medicine, Global Health Innovative Technology Fund closely related to M. vaccae

Whole cell, heat-inactivated Mycobacterium obuense, a nontuberculous mycobacterium

$\begin{array}{ll}\text { MIP; Cadila, } & \text { Whole cell, } \\ \text { Indian Council } & \text { heat-inactivated } \\ \text { of Medical } & \begin{array}{l}\text { Mycobacterium } \\ \text { indicus pranii }\end{array}\end{array}$

Therapeutic

\section{IFN $\gamma$-expressing} $\mathrm{CD4}{ }^{+} \mathrm{T}$ cells directed to different purified mycobacteria antigens

Therapeutic Not reported Not reported observed in $\lg C$ responses to $16 \mathrm{kDa}$ or $38 \mathrm{kDa}$ antigens

\section{Not known}

Phase III results expected in 2019 (ClinicalTrials.gov NCT01979900)

Prophylactic, Elevated IFN $\gamma \quad$ IgG responses postexposure levels and lym- to lipoarabinoand therapeutic phoproliferative mannan responses to stimulation with sonicated M. vaccae

Therapeutic Not known Not known

\section{$39 \%(95 \%$ \\ $\mathrm{Cl} 4-61 \%)$ count $>200$ cells per $\mu$ and BCG scar}

Phase II; phase Ilb HIV-positive infection ongoing patients (ClinicalTrials.gov with $\mathrm{CD}^{+} \quad \mathrm{NCT02712424)}$ 
Table 1 (cont.) | Tuberculosis vaccine candidates that are currently in clinical trials or have recently completed clinical trials

\begin{tabular}{|c|c|c|c|c|c|c|c|}
\hline $\begin{array}{l}\text { Candidate and } \\
\text { developers }\end{array}$ & $\begin{array}{l}\text { Antigens (genes } \\
\text { and function), } \\
\text { vector or } \\
\text { formulation }\end{array}$ & $\begin{array}{l}\text { Mode of } \\
\text { immunization }\end{array}$ & $\begin{array}{l}\text { Vaccine- } \\
\text { induced T cell } \\
\text { response }\end{array}$ & $\begin{array}{l}\text { Vaccine- } \\
\text { induced } \\
\text { antibody } \\
\text { response }\end{array}$ & Efficacy & $\begin{array}{l}\text { Development } \\
\text { status }\end{array}$ & Refs \\
\hline \multicolumn{8}{|c|}{ Adjuvanted protein subunit vaccine (cont.) } \\
\hline $\begin{array}{l}\text { H4:IC31; Sanofi, } \\
\text { Statens Serum } \\
\text { Institut, Valneva, } \\
\text { Aeras }\end{array}$ & $\begin{array}{l}\text { Ag85B (Rv1886c; } \\
\text { mycolyl } \\
\text { transferase) and } \\
\text { TB10.4 (Rv0288; } \\
\text { ESAT family } \\
\text { protein) and } \\
\text { IC31 adjuvant, } \\
\text { consisting of } \\
\text { positively charged } \\
\text { peptide-based } \\
\text { particles and } \\
\text { the non-CpG } \\
\text { immunostimulatory } \\
\text { oligonucleotide } \\
\text { ODN1a }\end{array}$ & $\begin{array}{l}\text { Prophylactic } \\
\text { and } \\
\text { postexposure }\end{array}$ & $\begin{array}{l}\text { CD4 }{ }^{+} T \text { cells co- } \\
\text { expressing TNF } \\
\text { and IL-2 or IFN } \gamma \text {, } \\
\text { TNF and IL-2; } \\
\text { absent or very } \\
\text { low } \mathrm{CD}^{+} \mathrm{T} \text { cell } \\
\text { responses }\end{array}$ & Not reported & $\begin{array}{l}30.5 \%(95 \% \\
\mathrm{Cl}-15.8 \% \\
\text { to } 58.3 \%) \\
\text { against } \\
\text { sustained } \\
\text { IGRA } \\
\text { conversion }\end{array}$ & $\begin{array}{l}\text { Phase Ilb trials } \\
\text { completed }\end{array}$ & $11,117,118$ \\
\hline $\begin{array}{l}\text { H56:IC31; } \\
\text { Statens Serum } \\
\text { Institut, Valneva, } \\
\text { Aeras }\end{array}$ & $\begin{array}{l}\text { Ag85B (Rv1886c; } \\
\text { mycolyl } \\
\text { transferase), ESAT6 } \\
\text { (Rv3875; ESAT } \\
\text { family protein) } \\
\text { and Rv2660c } \\
\text { (hypothesized to } \\
\text { be a stress-related } \\
\text { protein and IC31 } \\
\text { adjuvant) }\end{array}$ & $\begin{array}{l}\text { Prophylactic, } \\
\text { postexposure } \\
\text { and therapeutic }\end{array}$ & $\begin{array}{l}\text { CD4 }{ }^{+} \text {T cells co- } \\
\text { expressing TNF } \\
\text { and IL-2 or IFN } \gamma \text {, } \\
\text { TNF and IL-2. In } \\
\text { Mtb-infected } \\
\text { individuals, IFN } \gamma \text {, } \\
\text { TNF and IL-2 co- } \\
\text { expressing CD4 }{ }^{+} \\
\text {T cells; absent or } \\
\text { very low CD } 8^{+} \\
\text {T cell responses }\end{array}$ & Not reported & NA & $\begin{array}{l}\text { Phase Il prevention } \\
\text { of TB recurrence } \\
\text { trial ongoing } \\
\text { (ClinicalTrials.gov } \\
\text { NCT03512249) }\end{array}$ & $79,119-122$ \\
\hline $\begin{array}{l}\text { ID93 + GLA- } \\
\text { SE; Infectious } \\
\text { Disease } \\
\text { Research } \\
\text { Institute, } \\
\text { Quratis, } \\
\text { Wellcome Trust }\end{array}$ & $\begin{array}{l}\text { Rv1813 } \\
\text { (hypothesized to be } \\
\text { a secreted protein), } \\
\text { Rv2608 (belongs to } \\
\text { the PE and/or PPE } \\
\text { family of proteins), } \\
\text { Rv3619 and Rv3620 } \\
\text { (ESAT6 family } \\
\text { members) and GLA- } \\
\text { SE (TLR4 agonist) } \\
\text { in a squalene- } \\
\text { in-water emulsion }\end{array}$ & $\begin{array}{l}\text { Prophylactic, } \\
\text { postexposure } \\
\text { and therapeutic }\end{array}$ & $\begin{array}{l}\text { CD4 } 4^{+} T \text { cells } \\
\text { expressing IFN } \gamma \text {, } \\
\text { TNF and IL-2; } \\
\text { absent or very } \\
\text { low CD } 8^{+} \text {T cell } \\
\text { responses }\end{array}$ & $\begin{array}{l}\text { High levels of } \\
\text { lgG1 and lgG3 } \\
\text { responses to } \\
\text { Rv1813 (most } \\
\text { immunogenic) as } \\
\text { well as the other } \\
\text { three antigens }\end{array}$ & NA & $\begin{array}{l}\text { Phase II trial in } \\
\text { adults with cured TB } \\
\text { disease completed } \\
\text { (ClinicalTrials.gov } \\
\text { NCT02465216) }\end{array}$ & \\
\hline \multicolumn{8}{|c|}{ Viral vectored vaccines } \\
\hline $\begin{array}{l}\text { MVA85A; Oxford } \\
\text { University, Aeras }\end{array}$ & $\begin{array}{l}\text { Ag85A (Rv3804c; } \\
\text { mycolyl } \\
\text { transferase) and } \\
\text { recombinant } \\
\text { vaccinia virus }\end{array}$ & $\begin{array}{l}\text { Prophylactic, } \\
\text { prophylactic } \\
\text { and } \\
\text { postexposure }\end{array}$ & $\begin{array}{l}\mathrm{CD}^{+} \mathrm{T} \text { cells co- } \\
\text { expressing IFN } \gamma \text {, } \\
\text { TNF and IL-2; } \\
\text { absent or very } \\
\text { low } \mathrm{CD} 8^{+} \mathrm{T} \text { cell } \\
\text { responses }\end{array}$ & Not reported & $\begin{array}{l}17.3 \%(95 \% \\
\mathrm{Cl}-31.9 \% \\
\text { to } 48.2 \%) \\
\text { against TB } \\
\text { disease; } \\
-3.8 \%(95 \% \\
\mathrm{Cl}-28.1 \% \\
\text { to } 15.9 \%) \\
\text { against IGRA } \\
\text { conversion }\end{array}$ & $\begin{array}{l}\text { Phase II aerosol } \\
\text { administration } \\
\text { trials ongoing } \\
\text { (ClinicalTrials.gov } \\
\text { NCT02532036) }\end{array}$ & $10,27,125,126$ \\
\hline $\begin{array}{l}\text { Ad5Ag85A; } \\
\text { McMaster } \\
\text { University, } \\
\text { CanSino }\end{array}$ & $\begin{array}{l}\text { Ag85A (Rv3804c; } \\
\text { mycolyl } \\
\text { transferase) and } \\
\text { recombinant } \\
\text { adenovirus } \\
\text { serotype 5 }\end{array}$ & $\begin{array}{l}\text { Prophylactic } \\
\text { and } \\
\text { postexposure }\end{array}$ & $\begin{array}{l}C D 4^{+} \text {and } \\
C D 8^{+} \text {cells } \\
\text { expressing } \\
\mathrm{T}_{\mathrm{H}_{1} 1 \text {-type }} \\
\text { cytokines }\end{array}$ & Not reported & NA & $\begin{array}{l}\text { Phase I/II } \\
\text { trials ongoing } \\
\text { (ClinicalTrials.gov } \\
\text { NCT02337270) }\end{array}$ & \\
\hline
\end{tabular}

BCG, Mycobacterium bovis bacillus Calmette-Guérin; IGRA, IFN $\gamma$ release assay; M. vaccae, Mycobacterium vaccae; Mtb, Mycobacterium tuberculosis; NA, not available; TB, tuberculosis; TBVI, Tuberculosis Vaccine Initiative; $\mathrm{T}_{\mathrm{H}} 1$, T helper 1.

clinical testing include H4:IC31, H56:IC31, ID93 + GLA$\mathrm{SE}$ and $\mathrm{M} 72 / \mathrm{AS} 1_{\mathrm{E}}$. Some of these vaccines are also tested as therapeutic vaccines (for example, H56:IC31 and ID93 + GLA-SE) to prevent recurrence in patients who have completed chemotherapy for active TB.
Viral vectored vaccines. Live, attenuated, nonreplicating viruses can be engineered to deliver genes encoding the antigens of interest into host cells. Such vaccines allow for the intracellular production of the antigen in vivo and activate cells of the innate immune 
Chemotherapy for active TB Drug-sensitive tuberculosis (TB) disease is typically treated with a 4-drug regimen of rifampicin isoniazid, pyrazinamide and ethambutol for 2 months (the intensive phase of treatment), followed by isoniazid and rifampicin for 4 months (the continuation phase).

IFN $\gamma$ release assay (IGRA). A test for infection with Mycobacterium tuberculosis (Mtb) that measures IFN $\gamma$ release by $T$ cells after stimulation of blood or peripheral blood mononuclear cells with Mtb-specific peptides. IGRA conversion is an efficacy outcome in clinical trials that test prevention of Mtb infection, defined as conversion to a positive test without reversion to negative status in the next 2 consecutive IGRA tests, 3 months apart (that is, 3 consecutive positive IGRA results). system and therefore do not need to be adjuvanted. Viral vectored vaccines are being developed as both prophylactic vaccines and postexposure vaccines that boost responses primed by BCG or Mtb infection. A potential problem with viral delivery is the induction of vectorspecific immunity that can interfere with subsequent booster vaccinations. Two viral vectored TB vaccine candidates, MVA85A and Ad5Ag85A, are currently in clinical testing in prime-boost combinations, including trials of the MVA85A candidate administered by aerosol to the airways.

\section{BCG revaccination - time to reconsider?}

Revaccination with BCG at different ages, but primarily in children, was practised for decades in several countries with limited evidence for its clinical value or cost-effectiveness ${ }^{73}$. Two large cluster-randomized controlled trials conducted in Brazil and Malawi evaluated BCG revaccination for the prevention of TB disease. Neither demonstrated efficacy ${ }^{74,75}$, resulting in World Health Organization (WHO) recommendations against this policy. Subsequent follow-up studies conducted as part of the REVAC study in Brazil have added a new layer of understanding to this disappointing result and suggest that prior mycobacterial sensitization is a major factor in preventing BCG revaccination efficacy in regions with a high prevalence of environmental mycobacteria exposure ${ }^{76}$ (FIG. 2). In the recent trial with the H4:IC31 subunit vaccine or BCG revaccination in Cape Town, South Africa, BCG revaccination provided significant protection (45\% efficacy) against sustained Mtb infection (measured as prevention of sustained IFN $\gamma$ release assay (IGRA) conversion for a follow-up period of 24 months in healthy adolescents who received a BCG prime in infancy $)^{11}$. The readout of prevention of sustained IGRA conversion may be interpreted in different ways, which are all indicative of protective immunity: the prevention of primary infection, the accelerated clearance of the bacilli after infection, the long-term containment of the primary infection below the IGRA cut-off level or even the prevention of reinfection during the observation period. Regardless of the mechanistic interpretation of this readout, BCG revaccination resulted in a surprisingly high efficacy signal in this study. A plausible explanation for this observation most likely relates to the fact that individuals with Mtbspecific responses at enrolment, as measured by IGRA, were rigorously excluded ${ }^{11,77}$ and that Cape Town is thought to be an area with low to modest NTM exposure levels ${ }^{78}$. Compared with the REVAC study in Brazil, the main source of potential sensitization in this trial population therefore most likely came from remaining immune responses to neonatal BCG vaccination 12-16 years previously. So, even though pre-existing mycobacteria-specific $\mathrm{T}$ cell responses were found to be common in trial participants in the H4:IC31-BCG revaccination study, the results suggest that, without continuous high-level exposure from environmental mycobacteria or LTBI, the levels of immunity that persist from neonatal BCG vaccination are modest and do not block the efficacy of BCG revaccination significantly in adolescents (FIG 2).

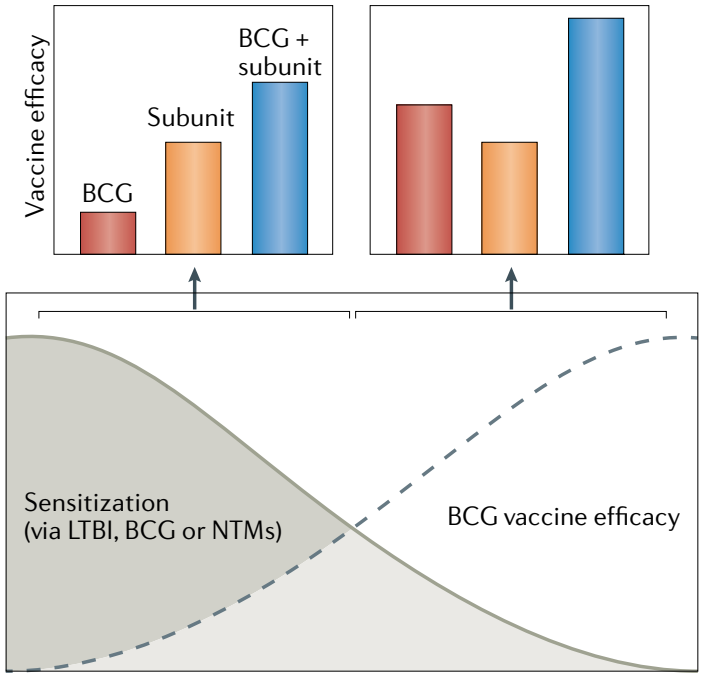

Fig. 2 | The effects of immunological sensitization to mycobacteria on vaccine efficacy. The hypothesized interaction between the magnitude of immune sensitization and vaccine efficacy by Mycobacterium bovis bacillus Calmette-Guérin (BCG) vaccination (red), adjuvanted protein subunit vaccines (orange) or a BCG-prime, subunit-boost strategy (blue) is shown. According to this model, BCG, and other live whole mycobacterial vaccines, are not efficacious in individuals with substantial prior immunological sensitization owing to latent tuberculosis infection (LTBI), recent $B C G$ vaccination or exposure to atypical non-tuberculous mycobacteria (NTMs) from the environment. Subunit vaccination, by comparison, would be efficacious in such a pre-sensitized population, as would a BCGrevaccination, subunit-boost strategy. In persons with low or no mycobacterial sensitization, the efficacy of $B C G$ vaccination is significantly increased, and the efficacy of subunit vaccination will be largely independent of the levels of sensitization, but the BCG-revaccination, subunit-boost strategy may provide synergistic effects that result in enhanced vaccine efficacy.

This efficacy signal therefore opens up consideration of BCG revaccination in certain settings as part of an overall improved TB vaccination strategy as previously suggested $^{78}$. Samples collected in the H4:IC31-BCG revaccination trial provide a unique opportunity to investigate whether the level of immune sensitization to NTMs at enrolment is associated with differences in the quality of the immune responses to the vaccine and/or protection against Mtb infection.

\section{Building on recent subunit vaccine success}

For the first time since the introduction of universal BCG vaccination into the WHO expanded programme for immunization in 1974, we have encouraging efficacy signals in trials of a TB vaccine ${ }^{11,12}$. In a phase IIb trial of healthy adolescents who received BCG in infancy but tested negative in the IGRA, vaccination with H4:IC31 was associated with $30.5 \%$ efficacy against sustained Mtb infection. This result was of statistical significance at the pre-defined statistical threshold of an $80 \% \mathrm{CI}$ (3.0-52.0\%), but not at a more rigorous 95\% CI (-15.8\% 
to $58.3 \%)^{11}$. Moreover, interim results of the ongoing phase IIb trial of $\mathrm{M} 72 / \mathrm{AS}_{\mathrm{E}} \mathrm{E}_{\mathrm{E}}$, conducted in 3,575 IGRA-positive adults, clearly illustrate that booster vaccination with a subunit vaccine can protect against TB disease in highly sensitized individuals with Mtb infection. This trial, which was conducted in HIV-negative adults from Kenya, Zambia and South Africa, most of whom received neonatal BCG, accrued 10 patients with microbiologically confirmed pulmonary TB into the $\mathrm{M} 72 / \mathrm{AS}_{\mathrm{E}}$ group and 22 patients into the placebo group, translating to an overall vaccine efficacy of $54.0 \%$ (95\% CI 13.9-75.4\%) ${ }^{12}$. An important consideration when interpreting the trial results of $\mathrm{M} 72 / \mathrm{ASO}_{\mathrm{E}}$ is how the level of $\mathrm{Mtb}$ exposure and reinfection of trial participants may have influenced the efficacy of the subunit vaccine. A recent analysis of the incubation period of TB suggested that the vast majority of clinical TB cases occur early, within 1-2 years following Mtb infection or reinfection. This is different from reactivation of $\mathrm{Mtb}$, which typically happens much later after a long period of latent infection ${ }^{3}$. The recent efficacy trial was conducted in settings with high Mtb infection rates where reinfection with Mtb is likely to be a frequent occurrence. Understanding whether the vaccine protected against reactivation disease or progression to disease following reinfection is likely to be important and will no doubt be the subject of investigation in coming years.

Whether the levels of efficacy observed in the H4:IC31-BCG and M72/AS01 $1_{\mathrm{E}}$ trials are sufficient and persist long enough for programmatic implementation of the vaccines in their present form is an important question, especially because the reports from each trial followed trial participants for only 2 years. However, combined into a prime-boost strategy with BCG vaccination, novel subunit vaccines may promote a robust response that could significantly add to the efficacy of the BCG vaccine and compensate for its failures in sensitized populations. In accordance with the model in FIG. 2, induction of immunity by BCG is either blocked or masked by high levels of pre-existing $\mathrm{T}$ cellmediated immune responses. By contrast, comparison of $\mathrm{H} 56: \mathrm{IC} 31$ or $\mathrm{M} 72 / \mathrm{ASO}_{\mathrm{E}}$ vaccination in naive versus LTBI individuals indicated that these subunit vaccines can markedly boost BCG-induced and Mtb-primed immune responses ${ }^{79-81}$. Therefore, a combined BCG revaccination and/or subunit vaccine strategy may have great potential in adult and/or adolescent populations.

\section{Conclusion and future perspectives}

The large number of different vaccine candidates and their advanced stages in clinical development denote a unique and exciting phase in TB vaccine research. There are also a large number of novel vaccine candidates in preclinical development, including more recently developed vaccine formats such as DNA vaccines, new adjuvants and delivery systems and combination vaccines. It is important that the most promising of these new candidates are advanced to efficacy studies in animals and clinical testing to augment the pipeline of TB vaccine candidates and concepts.

However, a notable limitation of the current clinical development landscape is a lack of inter-trial harmonization or standardization, which precludes a direct comparison of the immunological outcomes of different TB vaccine candidates. A recent analysis attempted to tackle this problem by comparing antigenspecific $\mathrm{CD}^{+}$and $\mathrm{CD} 8^{+} \mathrm{T}$ cell responses induced by BCG and six of the novel TB vaccine candidates, including MVA85A, AERAS-402, H1:IC31, H56:IC31, $\mathrm{M} 72 / \mathrm{AS} 1_{\mathrm{E}}$ and ID93 + GLA-SE. The investigators retrieved published data on antigen-specific $\mathrm{T}$ cell responses from clinical trials completed in adolescents or adults at a single trial site in South Africa ${ }^{82}$. The results show that the magnitude of vaccine-induced $\mathrm{T}_{\mathrm{H}} 1$ cell-polarized $\mathrm{CD}^{+}{ }^{+} \mathrm{T}$ cell responses measured several months after vaccination was the $T$ cell response feature that diverged the most between the different candidates. Unlike the response magnitude, co-expression profiles of IFN $\gamma$, TNF and IL- 2 by $\mathrm{CD} 4{ }^{+} \mathrm{T}$ cells suggested a relative lack of functional diversity in responses induced by the different vaccine candidates (see TABLE 1). Interestingly, the analyses suggested that $\mathrm{M} 72 / \mathrm{AS} 01_{\mathrm{E}}$ induced the highest antigen-specific memory $\mathrm{CD} 4^{+}$cell response among the candidates. Unfortunately, the study did not include results from whole cell or live vaccine candidates, which are known to induce a more diverse and broader repertoire of immune responses.

Overall, the recent positive clinical trial data referred to above represent a very important milestone in international efforts to develop a novel efficacious TB vaccine. These successes illustrate that $\mathrm{TB}$ vaccine research is on the right track and will be able to deliver a muchneeded improved vaccine strategy that is so critical for controlling the global TB epidemic. It is critical that the field moves forward with urgency towards phase III licensure trials so that an impact on the epidemic can be achieved swiftly. These findings therefore signal the end of the 'post-MVA85A period' of fundamental doubts about both the usefulness of the TB vaccine research strategy and the TB animal models in vaccine discovery $^{83}$. The M72/ASO1 ${ }_{\mathrm{E}}$ vaccine contains only two antigens, and the next generation of vaccines may be improved by adding more antigens to increase immune coverage and avoid the risk of escape. The efficacy signal observed with $\mathrm{M} 72 / \mathrm{ASO}_{\mathrm{E}}$ will likely also establish the $\mathrm{M} 72 / \mathrm{ASO}_{\mathrm{E}}$-induced protection as a minimum benchmark in preclinical animal models. As discussed above, many subunit vaccine candidates appear to induce a response that is typically characterized by early differentiated $\mathrm{CD}^{+} \mathrm{T}_{\mathrm{CM}}$ and $\mathrm{T}_{\mathrm{EM}}$ cells, whereas it seems that both viral and live mycobacterial vectors promote a more differentiated $\mathrm{CD} 4^{+} \mathrm{T}_{\mathrm{EFF}}$ cell response $\mathrm{e}^{27,52,54,82,84,85}$. It will therefore be important to agree on a standard set of parameters that would allow an accurate comparison between studies and vaccines to determine whether this is a reproducible pattern in clinical trials. Recent results of preclinical studies using a recombinant human cytomegalovirus encoding several Mtb T cell antigens have shown impressive protection in an NHP model, where prophylactic vaccination prevented infection in one-third of experimentally infected rhesus macaques ${ }^{86}$. Because cytomegalovirus vectored vaccines establish a persistent lifelong infection and induce a high level of antigen-specific $\mathrm{CD} 4^{+}$and $\mathrm{CD} 8^{+} \mathrm{T}$ cell responses, these 
findings suggest that, in addition to T cell differentiation as discussed above, the sheer size of the pool of $\mathrm{Mtb}$ specific $\mathrm{CD} 4^{+} \mathrm{T}$ cells has an impact on protection. This is also supported by the $\mathrm{M} 72 / \mathrm{ASO} 1_{\mathrm{E}}$ trial results, as this vaccine promotes a high frequency of antigen-specific $\mathrm{T}$ cells. However, more is not always better, and there is a risk of less protection and insufficient immune memory or even of inflicting immunopathology with vaccines that induce very strong $\mathrm{T}$ cell responses, particularly when used in the postexposure setting in individuals with LTBI. With an efficacy signal in young adolescents and/or adults from both BCG revaccination and subunit vaccine studies, it is intriguing to speculate whether the combination of both, administered sequentially or simultaneously ${ }^{87}$, may pave the way for a vaccination strategy that protects both uninfected and infected people while providing the possibility of a synergistic effect for inducing more diverse and broader-ranging immune responses. If an additive effect can be demonstrated, the combination of BCG and subunit vaccines may represent a new strategy that elevates the efficacy signal into a range that triggers clinical implementation.

Published online 21 May 2019
1. World Health Organization. Global tuberculosis report 2018 (WHO, 2018)

2. Houben, R. M. $\&$ Dodd, P. J. The global burden of latent tuberculosis infection: a re-estimation using mathematical modelling. PLOS Med. 13, e1002152 (2016).

3. Behr, M. A., Edelstein, P. H. \& Ramakrishnan, L. Revisiting the timetable of tuberculosis. BMJ 362 k2738 (2018).

4. Barry, C. E. et al. The spectrum of latent tuberculosis: rethinking the biology and intervention strategies. Nat. Rev. Microbiol. 7, 845-855 (2009).

5. Robertson, B. D. et al. Detection and treatment of subclinical tuberculosis. Tuberculosis (Edinb.) 92, 447-452 (2012)

6. Pai, M. et al. Tuberculosis. Nat. Rev. Dis. Primers 2 16076 (2016)

7. Drain, P. K. et al. Incipient and subclinical tuberculosis a clinical review of early stages and progression of infection. Clin. Microbiol. Rev. 31, e00021-18 (2018).

8. Scriba, T. J. et al. Sequential inflammatory processes define human progression from M. tuberculosis infection to tuberculosis disease. PLOS Pathog. 13, e1006687 (2017).

9. Hunter, R. L. The pathogenesis of tuberculosis: the early infiltrate of post-primary (adult pulmonary) tuberculosis: a distinct disease entity. Front. Immunol. 9, 2108 (2018)

10. Tameris, M. D. et al. Safety and efficacy of MVA85A, a new tuberculosis vaccine, in infants previously vaccinated with BCG: a randomised, placebo-controlled phase $2 \mathrm{~b}$ trial. Lancet 381, 1021-1028 (2013). This paper reports the safety, immunogenicity and efficacy of the first viral vectored TB vaccine candidate, MVA85A, in infants who received BCG at birth. No protection against Mtb infection or TB disease was observed.

11. Nemes, E. et al. Prevention of M. tuberculosis infection with $\mathrm{H} 4: \mathrm{IC} 31$ vaccine or BCG revaccination. N. Engl. J. Med. 379, 138-149 (2018).

This paper reports the results of a phase IIb prevention of Mtb infection trial and demonstrates that BCG revaccination affords significant protection against sustained IGRA conversion in South African adolescents who received BCG at birth

12. Van Der Meeren, V. D. M. et al. Phase $2 b$ controlled trial of M72/AS01E vaccine to prevent tuberculosis. N. Engl. J. Med. 379, 1621-1634 (2018). This phase IIb trial in IGRA-positive adults from three African countries demonstrates for the first time that a protein subunit TB vaccine candidate can protect against TB disease.

13. Cambier, C. J. et al. Mycobacteria manipulate macrophage recruitment through coordinated use of membrane lipids. Nature 505, 218-222 (2014).

14. Shafiani, S., Tucker-Heard, G., Kariyone, A., Takatsu, K \& Urdahl, K. B. Pathogen-specific regulatory T cells delay the arrival of effector T cells in the lung during early tuberculosis. J. Exp. Med. 207, 1409-1420 (2010)

15. Ernst, J. D. Mechanisms of M. tuberculosis immune evasion as challenges to TB vaccine design. Cell Host Microbe 24, 34-42 (2018).

16. Reiley, W. W. et al. ESAT-6-specific CD4 T cell responses to aerosol Mycobacterium tuberculosis infection are initiated in the mediastinal lymph nodes. Proc. Natl Acad. Sci. USA 105, 10961-10966 (2008).

17. Poulsen, A. Some clinical features of tuberculosis. 1. Incubation period. Acta Tuberc. Scand. 24, 311-346 (1950).
18. Wallgren, A. The time-table of tuberculosis. Tubercle 29, 245-251 (1948).

19. Khader, S. A. et al. IL-23 and IL-17 in the establishment of protective pulmonary $\mathrm{CD} 4+\mathrm{T}$ cell responses after vaccination and during Mycobacterium tuberculosis challenge. Nat Immunol 8, 369-377 (2007)

20. Woodworth, J. S. et al. Subunit vaccine H56/CAF01 induces a population of circulating CD4 T cells that traffic into the Mycobacterium tuberculosis-infected lung. Mucosal Immunol. 10, 555-564 (2017).

21. Ahmed, $M$. et al. A novel nanoemulsion vaccine induces mucosal interleukin-17 responses and confers protection upon Mycobacterium tuberculosis challenge in mice. Vaccine 35, 4983-4989 (2017).

22. Dijkman, K. et al. Prevention of tuberculosis infection and disease by local BCG in repeatedly exposed rhesus macaques. Nat. Med. 25, 255-262 (2019). This paper demonstrates in an NHP model that mucosal BCG vaccination affords high-level protection against repeated, low-dose infection and identifies mucosal antigen-specific $T_{H} 1$ cell and/or $T_{H} 17$ cell and IgA responses as putative COP

23. Nunes-Alves, $C$. et al. In search of a new paradigm for protective immunity to TB. Nat. Rev. Microbiol. 12 , 289-299 (2014)

24. Sakai, S et al. CD4 T cell-derived IFN-gamma plays a minimal role in control of pulmonary Mycobacterium tuberculosis infection and must be actively repressed by PD-1 to prevent lethal disease. PLOS Pathog. 12 e1005667 (2016)

25. Goldsack, L. \& Kirman, J. R. Half-truths and selective memory: interferon gamma, CD4 ${ }^{+} \mathrm{T}$ cells and protective memory against tuberculosis. Tuberculosis (Edinb.) 87, 465-473 (2007).

26. Fletcher, H. A. et al. T cell activation is an immune correlate of risk in BCG vaccinated infants.

Nat. Commun. 7, 11290 (2016).

This paper investigates immunological correlates of risk of TB in infants who participated in the first phase Ilb trial of the MVA85A vaccine candidate. BCG-specific IFN $\gamma$-expressing cells and Ag85Aspecific IgG antibody titres correlate with low risk of progression to TB, while HLA-DR ${ }^{+} \mathrm{CD}^{+} \mathrm{T}$ cells correlate with high risk of progression to TB.

27. Tameris, M. et al. The candidate TB vaccine, MVA85A induces highly durable Th 1 responses. PLOS ONE 9, e87340 (2014).

28. Kagina, B. M. et al. Specific T cell frequency and cytokine expression profile do not correlate with protection against tuberculosis after bacillus Calmette-Guerin vaccination of newborns. Am. J. Respir Crit Care Med 182, 1073-1079 (2010)

29. Sallin, M. A. et al. Host resistance to pulmonary Mycobacterium tuberculosis infection requires CD153 expression. Nat. Microbiol. 3, 1198-1205 (2018).

30. Billeskov, R., Vingsbo-Lundberg, C., Andersen, P. \& Dietrich, J. Induction of CD8 T cells against a novel epitope in TB10.4: correlation with mycobacterial virulence and the presence of a functional region of difference-1. J. Immunol. 179, 3973-3981 (2007).

31. Lin, P. L. \& Flynn, J. L. CD8 T cells and Mycobacterium tuberculosis infection. Semin. Immunopathol. 37, 239-249 (2015)

32. Chen, C. Y. et al. A critical role for CD8 T cells in a nonhuman primate model of tuberculosis. PLOS Pathog. 5, e 1000392 (2009).

33. Lindenstrom, T., Aagaard, C., Christensen, D. Agger, E. M. \& Andersen, P. High-frequency vaccineinduced $C D 8^{+} T$ cells specific for an epitope naturally processed during infection with Mycobacterium tuberculosis do not confer protection. Eur. J. Immunol. 44, 1699-1709 (2014)

34. Yang, J. D. et al. Mycobacterium tuberculosis-specific $\mathrm{CD}^{+}$and $\mathrm{CD}^{+} \mathrm{T}$ cells differ in their capacity to recognize infected macrophages. PLOS Pathog. 14, e1007060 (2018)

35. Nyendak, M. et al. Adenovirally-induced polyfunctional $T$ cells do not necessarily recognize the infected target: lessons from a phase I trial of the AERAS-402 vaccine. Sci. Rep. 6, 36355 (2016).

36. Lu, L. L. et al. A functional role for antibodies in tuberculosis. Cell 167, 433-443 (2016).

37. Abebe, F. et al. IgA and IgG against Mycobacterium tuberculosis Rv2031 discriminate between pulmonary tuberculosis patients, Mycobacterium tuberculosis-infected and non-infected individuals. PLOS ONE 13, e0190989 (2018).

38. Portal-Celhay, C. et al. Mycobacterium tuberculosis EsxH inhibits ESCRT-dependent CD4 ${ }^{+} \mathrm{T}$ cell activation Nat. Microbiol. 2, 16232 (2016).

39. Bold, T. D., Banaei, N., Wolf, A. J. \& Ernst, J. D. Suboptimal activation of antigen-specific $\mathrm{CD}^{+}$effector cells enables persistence of $\mathrm{M}$. tuberculosis in vivo. PLOS Pathog. 7, e1002063 (2011)

This study demonstrates that Mtb is recognized in the first phase of infection in the mouse model by protective $\mathrm{T}$ cells recognizing the Ag85 antigen but that bacterial downregulation of this antigen allows bacterial persistence in the presence of antigen-specific $T$ cells.

40. Srivastava, S., Grace, P. S. \& Ernst, J. D. Antigen export reduces antigen presentation and limits $\mathrm{T}$ cell control of M. tuberculosis. Cell Host Microbe 19 , 44-54 (2016)

41. Heimbeck, J. Incidence of tuberculosis in young adult women with special reference to employment. Br. J. Tuberculosis 32, 154-166 (1938).

42. Andrews, J. R. et al. Risk of progression to active tuberculosis following reinfection with Mycobacterium tuberculosis. Clin. Infect. Dis. 54, 784-791 (2012). This meta-analysis of 18 human studies from the pre-chemotherapeutic era suggests that prior Mtb infection provides high-level protection against risk of progression to TB disease when individuals in contact with patients with TB are exposed to Mtb again.

43. Cadena, A. M. et al. Concurrent infection with Mycobacterium tuberculosis confers robust protection against secondary infection in macaques. PLOS Pathog 14, e 1007305 (2018).

44. Kaushal, D. et al. Mucosal vaccination with attenuated Mycobacterium tuberculosis induces strong central memory responses and protects against tuberculosis. Nat. Commun. 6, 8533 (2015)

45. Mpande, C. A. M. et al. Functional, antigen-specific stem cell memory (TSCM) $\mathrm{CD}^{+} \mathrm{T}$ cells are induced by human Mycobacterium tuberculosis infection. Front. Immunol. 9, 324 (2018).

46. Boer, M. C. et al. KLRG1 and PD-1 expression are increased on $\mathrm{T}$ cells following tuberculosis-treatment and identify cells with different proliferative capacities in BCG-vaccinated adults. Tuberculosis (Edinb.) 97 163-171 (2016)

47. Day, C. L. et al. Functional capacity of Mycobacterium tuberculosis-specific $\mathrm{T}$ cell responses in humans is associated with mycobacterial load. J. Immunol. 187 2222-2232 (2011)

48. Rozot, V. et al. Combined use of Mycobacterium tuberculosis-specific CD4 and CD8 T cell responses is a powerful diagnostic tool of active tuberculosis. Clin. Infect. Dis. 60, 432-437 (2015). 
49. Nikitina, I. Y. et al. Th1, Th17, and Th1Th 17 lymphocytes during tuberculosis: Th1 lymphocytes predominate and appear as low-differentiated $\mathrm{CXCR}^{+}{ }^{+} \mathrm{CR} 6{ }^{+}$cells in the blood and highly differentiated $\mathrm{CXCR} 3^{+/-}$CCR6 6 cells in the lungs. J. Immunol. 200, 2090-2103 (2018).

50. Jayaraman, P. et al. TIM3 mediates T cell exhaustion during Mycobacterium tuberculosis Infection. PLOS Pathog. 12, e1005490 (2016).

51. Reiley, W. W. et al. Distinct functions of antigenspecific CD4 T cells during murine Mycobacterium tuberculosis infection. Proc Natl Acad. Sci. USA 107 19408-19413 (2010).

52. Lindenstrom, T., Knudsen, N. P., Agger, E. M. \& Andersen, P. Control of chronic Mycobacterium tuberculosis infection by CD4 KLRG 1 IL-2-secreting central memory cells. J. Immunol. 190, 6311-6319 (2013).

This study demonstrates the importance of vaccinepromoted $T_{C M}$ cells in the long-term maintenance of protection against chronic Mtb infection in the mouse model.

53. Orme, I. M. The Achilles heel of BCG. Tuberculosis (Edinb.) 90, 329-332 (2010)

54. Lindenstrom, T. et al. T cells primed by live mycobacteria versus a tuberculosis subunit vaccine exhibit distinct functional properties. EBioMedicine 27, 27-39 (2018)

This study demonstrates that live mycobacteria (either Mtb or BCG) prime T cells in mice that are more differentiated than $\mathrm{T}$ cells induced in response to subunit vaccines and that this difference has profound influence on the migration of the Mtb-specific T cells to the lung parenchyma.

55. Sakai, S. et al. Cutting edge: control of Mycobacterium tuberculosis infection by a subset of lung parenchymahoming CD4 T cells. J. Immunol. 192, 2965-2969 (2014)

This paper is the first to demonstrate that, in the mouse model, less differentiated KLRG1-CXCR3 $\mathbf{T}_{C M}$ cell-like cells readily migrate into the Mtbinfected lung parenchyma, in contrast to KLRG $1^{+}$CXCR3 ${ }^{-} T_{\text {EFF }}$ cells.

56. Torrado, E. et al. Interleukin $27 \mathrm{R}$ regulates $\mathrm{CD} 4^{+} \mathrm{T}$ cell phenotype and impacts protective immunity during Mycobacterium tuberculosis infection. J. Exp. Med. 212, 1449-1463 (2015).

57. Woodworth, J. S. et al. Protective CD4 T cells targeting cryptic epitopes of Mycobacterium tuberculosis resist infection-driven terminal differentiation. J. Immunol. 192, 3247-3258 (2014).

58. Sallin, M. A. et al. Th1 differentiation drives the accumulation of intravascular, non-protective CD4 T cells during tuberculosis. Cell Rep. 18, 3091-3104 (2017).

59. Behar, S. M., Carpenter, S. M., Booty, M. G., Barber, D. L. \& Jayaraman, P. Orchestration of pulmonary $\mathrm{T}$ cell immunity during Mycobacterium tuberculosis infection: immunity interruptus. Semin. Immunol. 26, 559-577 (2014).

60. Urdahl, K. B. Understanding and overcoming the barriers to T cell-mediated immunity against tuberculosis. Semin. Immunol. 26, 578-587 (2014).

61. Rogerson, B. J. et al. Expression levels of Mycobacterium tuberculosis antigen-encoding genes versus production levels of antigen-specific $T$ cells during stationary level lung infection in mice. Immunology 118, 195-201 (2006).

62. Shi, L., North, R. \& Gennaro, M. L. Effect of growth state on transcription levels of genes encoding major secreted antigens of Mycobacterium tuberculosis in the mouse lung. Infect. Immun. 72, 2420-2424 (2004).

63. Moguche, A. O. et al. Antigen availability shapes T cell differentiation and function during tuberculosis. Cell Host Microbe 21, 695-706 (2017). This paper demonstrates that the Mtb antigens Ag85B and ESAT6 are differentially expressed during infection in mice and humans. CD4 ${ }^{+} \mathrm{T}$ cells that recognize these antigens exhibit distinct patterns of differentiation, and their capacities to mediate protective immunity are restricted in different ways.

64. Coscolla, M. et al. M. tuberculosis T cell epitope analysis reveals paucity of antigenic variation and identifies rare variable TB antigens. Cell Host Microbe 18, 538-548 (2015)

65. Woodworth, J. S. \& Andersen, P. Reprogramming the $\mathrm{T}$ cell response to tuberculosis. Trends Immunol. 37 81-83 (2016)

66. Comas, I. et al. Human T cell epitopes of Mycobacterium tuberculosis are evolutionarily hyperconserved. Nat. Genet. 42, 498-503 (2010).
67. Harari, A., Vallelian, F. \& Pantaleo, G. Phenotypic heterogeneity of antigen-specific CD4 T cells under different conditions of antigen persistence and antigen Ioad. Eur. J. Immunol. 34, 3525-3533 (2004).

68. Vordermeier, H. M. et al. Correlation of ESAT-6-specific gamma interferon production with pathology in cattle following Mycobacterium bovis BCG vaccination against experimental bovine tuberculosis. Infect. Immun. 70 3026-3032 (2002).

69. Langermans, J. A. et al. Divergent effect of bacillus Calmette-Guerin (BCG) vaccination on Mycobacterium tuberculosis infection in highly related macaque species: implications for primate models in tuberculosis vaccine research. Proc. Natl Acad. Sci. USA 98, 11497-11502 (2001).

70. Barber, D. L., Mayer-Barber, K. D., Feng, C. G. Sharpe, A. H. \& Sher, A. CD4 T cells promote rather than control tuberculosis in the absence of PD-1 mediated inhibition. J. Immunol. 186, 1598-1607 (2011).

71. Cruz, A. et al. Pathological role of interleukin 17 in mice subjected to repeated BCG vaccination after infection with Mycobacterium tuberculosis. J. Exp. Med. 207 1609-1616 (2010)

72. Billeskov, R. et al. High antigen dose is detrimental to post-exposure vaccine protection against tuberculosis Front. Immunol. 8, 1973 (2018).

73. World Health Organization. WHO statement on BCC revaccination for the prevention of tuberculosis. Bull. World Health Organ. 73, 805-806 (1995).

74. Rodrigues, L. C. et al. Effect of BCG revaccination on incidence of tuberculosis in school-aged children in Brazil: the BCG-REVAC cluster-randomised trial. Lancet 366, 1290-1295 (2005)

75. Karonga Prevention Trial Group. Randomised controlled trial of single BCG, repeated BCG, or combined BCG and killed Mycobacterium leprae vaccine for prevention of leprosy and tuberculosis in Malawi. Lancet 348 17-24 (1996)

76. Barreto, M. L. et al. Causes of variation in BCG vaccine efficacy: examining evidence from the BCG REVAC cluster randomized trial to explore the masking and the blocking hypotheses. Vaccine 32, 3759-3764 (2014).

This analysis of the BCG REVAC cluster-randomized trial in Brazil reports some protection against TB in Salvador and no protection in Manaus and shows that variability in BCG efficacy was high when BCG was administered to children of school age but absent when BCG was administered at birth. The study suggests that prior immunological sensitization blocks, rather than masks, the protective effects of BCG.

77. Nemes, E. et al. Optimization and interpretation of serial QuantiFERON testing to measure acquisition of Mycobacterium tuberculosis infection. Am. J. Respir. Crit. Care Med. 196, 638-648 (2017).

78. Dye, C. Making wider use of the world's most widely used vaccine: bacille Calmette-Guerin revaccination reconsidered. J. R. Soc. Interface 10, 20130365 (2013).

This paper discusses the considerations around strategies for utilizing BCG revaccination to achieve higher levels of protection against TB in different parts of the world

79. Suliman, S. et al. Dose optimization of H56:IC31 vaccine for TB endemic populations: a double-blind, placebo-controlled, dose-selection trial. Am. J. Respir. Crit. Care Med. 199, 220-231 (2018).

80. Day, C. L. et al. Induction and regulation of T cell immunity by the novel tuberculosis vaccine M72/AS0 in South African adults. Am. J. Respir. Crit. Care Med. 188, 492-502 (2013).

81. Penn-Nicholson, A. et al. Safety and immunogenicity of candidate vaccine M72/AS01E in adolescents in TB endemic setting. Vaccine 33, 4025-4034 (2015).

82. Rodo, M. J. et al. A comparison of antigen-specific $T$ cell responses induced by six novel tuberculosis vaccine candidates. PLOS Pathog. 15, e1007643 (2019).

83. Macleod, M. Learning lessons from MVA85A, a failed booster vaccine for BCG. BMJ 360, k66 (2018).

84. Billeskov, R., Christensen, J. P. Aagaard C. Andersen, P. \& Dietrich, J. Comparing adjuvanted $\mathrm{H} 28$ and modified vaccinia virus ankara expressing $\mathrm{H} 28$ in a mouse and a non-human primate tuberculosis model. PLOS ONE 8, e72185 (2013).

85. Leung-Theung-Long, S. et al. A novel MVA-based multiphasic vaccine for prevention or treatment of tuberculosis induces broad and multifunctional cell-mediated immunity in mice and primates. PLOS ONE 10, e0143552 (2015).
86. Hansen, S. G. et al. Prevention of tuberculosis in rhesus macaques by a cytomegalovirus-based vaccine. Nat. Med. 24, 130-143 (2018)

\section{This study demonstrates in NHPs that a novel,} cytomegalovirus-based TB vaccine candidate provides high-level protection against Mtb infection, disease progression and disease pathology.

87. Dietrich, J., Billeskov, R., Doherty, T. M. \& Andersen, P. Synergistic effect of bacillus Calmette Guerin and a tuberculosis subunit vaccine in cationic liposomes: increased immunogenicity and protection. J. Immunol. 178, 3721-3730 (2007)

88. Brosch, R. et al. Genome plasticity of BCG and impact on vaccine efficacy. Proc. Natl Acad. Sci. USA 104, 5596-5601 (2007).

89. Behr, M. A. et al. Comparative genomics of BCG vaccines by whole-genome DNA microarray. Science 284, 1520-1523 (1999)

90. Nieuwenhuizen, N. E. \& Kaufmann, S. H. E. Nextgeneration vaccines based on bacille Calmette-Guerin Front. Immunol. 9, 121 (2018)

91. Scriba, T. J et al. Vaccination against tuberculosis with whole-cell mycobacterial vaccines. J. Infect. Dis. $\mathbf{2 1 4}$, 659-664 (2016)

92. Kaufmann, E. et al. BCG educates hematopoietic stem cells to generate protective innate immunity against tuberculosis. Cell 172, 176-190 (2018).

93. Fine, P. E. Variation in protection by BCG: implications of and for heterologous immunity. Lancet 346 , 1339-1345 (1995).

94. Abubakar, I. et al. Systematic review and metaanalysis of the current evidence on the duration of protection by bacillus Calmette-Guerin vaccination against tuberculosis. Health Technol. Assess. 17, 1-372 (2013)

95. Aronson, N. E. et al. Long-term efficacy of BCG vaccine in American Indians and Alaska Natives: a 60-year follow-up study. JAMA 291, 2086-2091 (2004).

96. Nguipdop-Djomo, P., Heldal, E., Rodrigues, L. C., Abubakar, I. \& Mangtani, P. Duration of BCG protection against tuberculosis and change in effectiveness with time since vaccination in Norway: a retrospective population-based cohort study. Lancet Infect. Dis. 16, 219-226 (2016).

97. Palmer, C. E. \& Long, M. W. Effects of infection with atypical mycobacteria on BCG vaccination and tuberculosis. Am. Rev. Respir. Dis. 94, 553-568 (1966).

98. Mangtani, P. et al. Protection by BCG vaccine against tuberculosis: a systematic review of randomized controlled trials. Clin. Infect. Dis. 58, 470-480 (2014)

99. Andersen, P. \& Doherty, T. M. The success and failure of BCG - implications for a novel tuberculosis vaccine. Nat. Rev. Microbiol. 3, 656-662 (2005).

100. Hoefsloot, W. et al. The geographic diversity of nontuberculous mycobacteria isolated from pulmonary samples: an NTM-NET collaborative study. Eur. Respir. J. 42, 1604-1613 (2013).

101. von Reyn, C. F. BCG, latitude, and environmental mycobacteria. Clin. Infect. Dis. 59, 607-608 (2014).

102. Qin, L., Gilbert, P. B., Corey, L., McElrath, M. J. \& Self, S. G. A framework for assessing immunological correlates of protection in vaccine trials. J. Infect. Dis. 196, 1304-1312 (2007).

103. Jasenosky, L. D., Scriba, T. J., Hanekom, W. A. \& Goldfeld, A. E. T cells and adaptive immunity to Mycobacterium tuberculosis in humans. Immunol. Rev. 264, 74-87 (2015)

104. Voss, G. et al. Progress and challenges in TB vaccine development. F100ORes. 7, 199 (2018).

105. Nieuwenhuizen, N. E. et al. The recombinant bacille Calmette-Guerin vaccine VPM1002: ready for clinical efficacy testing. Front. Immunol. 8, 1147 (2017).

106. Loxton, A. G. et al. Safety and immunogenicity of the recombinant Mycobacterium bovis BCG vaccine VPM 1002 in HIV-unexposed newborn infants in South Africa. Clin. Vaccine Immunol. 24, e00439-16 (2017).

107. Arbues, A. et al. Construction, characterization and preclinical evaluation of MTBVAC, the first liveattenuated M. tuberculosis-based vaccine to enter clinical trials. Vaccine 31, 4867-4873 (2013).

108. Aguilo, N. et al. Reactogenicity to major tuberculosis antigens absent in BCG is linked to improved protection against Mycobacterium tuberculosis. Nat. Commun. 8, 16085 (2017)

109. Spertini, F. et al. Safety of human immunisation with a live-attenuated Mycobacterium tuberculosis vaccine: a randomised, double-blind, controlled phase I trial. Lancet Respir. Med. 3, 953-962 (2015).

110. Cardona, P. J. RUTI: a new chance to shorten the treatment of latent tuberculosis infection. Tuberculosis (Edinb.) 86, 273-289 (2006). 
111. Nell, A. S. et al. Safety, tolerability, and immunogenicity of the novel antituberculous vaccine RUTI: randomized, placebo-controlled phase II clinical trial in patients with latent tuberculosis infection. PLOS ONE 9, e89612 (2014).

112. Lahey, T. et al. Immunogenicity of a protective whole cell mycobacterial vaccine in HIV-infected adults: a phase III study in Tanzania. Vaccine 28, 7652-7658 (2010).

113. von Reyn, C. F. et al. Prevention of tuberculosis in bacille Calmette-Guerin-primed, HIV-infected adults boosted with an inactivated whole-cell mycobacterial vaccine. AIDS 24, 675-685 (2010)

114. Sharma, S. K. et al. Efficacy and safety of Mycobacterium indicus pranii as an adjunct therapy in category II pulmonary tuberculosis in a randomized trial. Sci. Rep. 7, 3354 (2017).

115. Mayosi, B. M. et al. Prednisolone and Mycobacterium indicus pranii in tuberculous pericarditis. N. Engl. J. Med. 371, 1121-1130 (2014).

116. Leroux-Roels, I. et al. Improved CD4 ${ }^{+} \mathrm{T}$ cell responses to Mycobacterium tuberculosis in PPD-negative adults by M72/AS01 as compared to the M72/AS02 and Mtb72F/AS02 tuberculosis candidate vaccine formulations: a randomized trial. Vaccine 31 2196-2206 (2013).

117. Dietrich, J. et al. Exchanging ESAT6 with TB 10.4 in an Ag85B fusion molecule-based tuberculosis subunit vaccine: efficient protection and ESAT6-based sensitive monitoring of vaccine efficacy. J. Immunol. 174 6332-6339 (2005).

118. Szabo, A. et al. The two-component adjuvant IC $31^{\circledR}$ boosts type I interferon production of human monocyte-derived dendritic cells via ligation of endosomal TLRs. PLOS ONE 8, e55264 (2013).

119. Aagaard, C. et al. A multistage tuberculosis vaccine that confers efficient protection before and after exposure. Nat. Med. 17, 189-194 (2011).

120. Hoang, T. et al. ESAT-6 (EsxA) and TB10.4 (EsxH) based vaccines for pre- and post-exposure tuberculosis vaccination. PLOS ONE 8, e80579 (2013).

121. Lin, P. L. et al. The multistage vaccine $\mathrm{H} 56$ boosts the effects of BCG to protect cynomolgus macaques against active tuberculosis and reactivation of latent Mycobacterium tuberculosis infection. J. Clin. Invest. 122, 303-314 (2012).

122. Luabeya, A. K. et al. First-in-human trial of the post-exposure tuberculosis vaccine H56:IC31 in Mycobacterium tuberculosis infected and non-infected healthy adults. Vaccine 33, 4130-4140 (2015).

123. Coler, R. N. et al. The TLR-4 agonist adjuvant, GLA-SE, improves magnitude and quality of immune responses elicited by the ID93 tuberculosis vaccine: firstin-human trial. NPJ Vaccines 3, 34 (2018)

124. Penn-Nicholson, A. et al. Safety and immunogenicity of the novel tuberculosis vaccine ID93 + GLA-SE in BCG-vaccinated healthy adults in South Africa: a randomised, double-blind, placebo-controlled phase 1 trial. Lancet Respir. Med. 6, 287-298 (2018).

125. Satti, I. et al. Safety and immunogenicity of a candidate tuberculosis vaccine MVA85A delivered by aerosol in BCG-vaccinated healthy adults: a phase 1 , double-blind, randomised controlled trial. Lancet Infect. Dis. 14, 939-946 (2014).
126. Scriba, T. J. et al. Dose-finding study of the novel tuberculosis vaccine, MVA85A, in healthy BCG vaccinated infants. J. Infect. Dis. 203, 1832-1843 (2011).

127. Jeyanathan, M. et al. Induction of an immuneprotective T-cell repertoire with diverse genetic coverage by a novel viral-vectored tuberculosis vaccine in humans. J. Infect. Dis. 214, 1996-2005 (2016).

\section{Acknowledgements}

The authors thank P. Højlund for expert secretarial assistance, K. Korsholm for the graphical layout and R. Mortensen and $\mathrm{J}$. Woodworth for valuable discussions and input on the content of the paper.

\section{Author contributions}

The authors contributed equally to all aspects of the article.

\section{Competing interests}

T.J.S. declares no competing interests. P.A. is a named co-inventor on patents covering the H56:IC31 tuberculosis vaccine. The patents are assigned to the Statens Serum Institute, a not for profit organization under the Danish Ministry of Health.

\section{Publisher's note}

Springer Nature remains neutral with regard to jurisdictional claims in published maps and institutional affiliations.

\section{Reviewer information}

Nature Reviews Immunology thanks P.-J. Cardona and other anonymous reviewer(s) for their contribution to the peer review of this work. 